\title{
The effect of using flashcards on ESL (English as a Second Language) students' ability to learn vocabulary
}

\author{
Saeed Mojarradi \\ Department of English Language and Linguistics, Islamic Azad University, Ahar Branch, Ahar, East Azarbaijan, Iran \\ E-mail: saeedmojaradi@outlook.com
}

Copyright ()$_{2014}$ S. Mojarradi. This is an open access article distributed under the Creative Commons Attribution License, which permits unrestricted use, distribution, and reproduction in any medium, provided the original work is properly cited.

\begin{abstract}
An increased vocabulary and good memory of such vocabulary could help students boost their knowledge of English and better manage conversation and writing skills. This research aims to evaluate two methods of learning using the technique of flashcards. Flashcards can either be bought, already prepared in bookstores, or students can make their own flashcards. Each of these aforementioned methods of acquiring flashcards has its own structure. In the latter technique, whereby prepared flashcards are used by students, there can be various effects on students' ability for learning vocabulary. This study was done to test pre-university students attending high school. Students were asked to answer pretest and post test examination questions. Finally the study showed us producing handmade flashcards is infact time-consuming task.
\end{abstract}

Keywords: Flash cards, Vocabulary, Word.

\section{Introduction}

A number of recent research studies have addressed lexical problems in language learning. Scholars such as Aleen [12] and Bowen [13] demonstrate that lexical problems frequently interfere with communication, such that communication breaks down when words are used innapropriately. The findings of these studies have prompted an increased interest in vocabulary learning as an important component of language acquisition (Eslahkar [3]).

According to Din and Wienk [11], language learning appproaches using flashcards present an effective training and learning method for high school teachers and students in chemistry, flashcards can also be used effectively as a teaching resource to help students learn and comprehend chemistry vocabulary (Eslahkar [3]).

A study has been done by Richard C. Yorkey in which information is presented on precise methods to learn and use words correctly (Yorkey [10]). The study reports methods using flashcards as follows: 1 - Write the new word on any convenient scrap of paper. This is not recommended. The scrap of paper may get lost or untidy piles of papers may accumulate, scattered in various places. 2 - The best method is to use file cards. This is also the most difficult method because it requires continuous neatness.

Many reaserchers found that learning vocabulary requires a strategic process. Learners should acquire this strategy and it should be compared with his or her first language system.

(Michael J. Lawson, Donald Hogben [8]) observed that students attempted to learn meanings of new words from the context of a sentence. Word context is therefore very important and words should be learnt within a context; accordingly, flashcards can help students achieve good results.

There is an idea that students who use readymade flashcards or prepared resources and devices to learn English words, rather than hand writing, can learn better; this assertion implies that students achieve better results by using traditional learning techniques.

Yorkey [10], presents a method for teaching vocabulary to English students using flashcards. The paper proposes that if students really want to expand their vocabulary then they need a system to record new words that is associated with the meanings of such words; and that these newly introduced words need to be reviewed regularly. 
The report by Yorkey [10] proposes that flashcards be made according to specific directions; step (A) Use a pack of 3 by 5 -inch file cards (either lined or unlined).

These can be purchased at any stationary store or college bookstore. (B) Write each new word you want to learn on a separate card. For filing purposes, the word should be printed neatly in large letters in the upper left-hand corner of the card. (C) On the same side of the card, copy from your dictionary the word's pronunciation, including stress marks. Also copy and label other parts of speech for the word. For example:

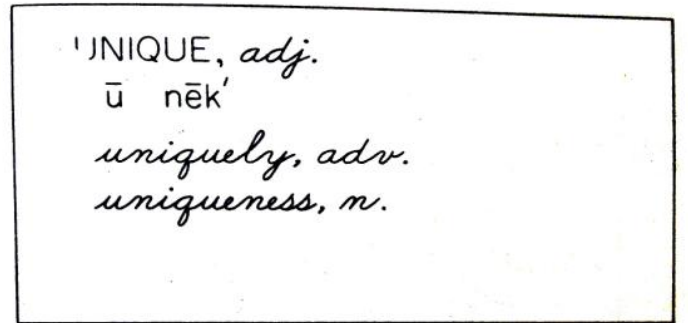

(D) On the opposite side of the card, write the definition (in English). Then

Write the sentence in which you read or hear the word. For example:

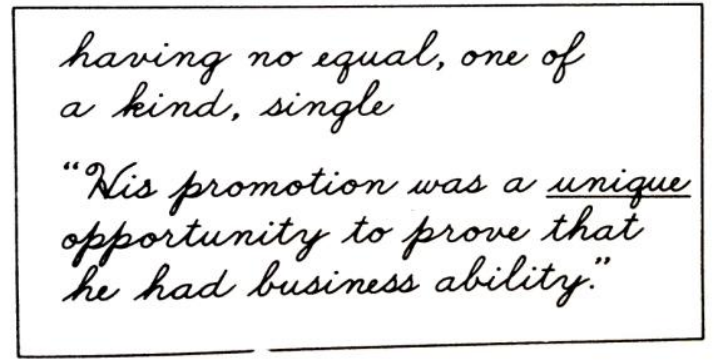

Fig. 1

E. Arrange your cards in alphabetical order.

Incidentally, many studies have been done about this way of learning words and none of them have made a comparison between the effects of making flash cards by students and buying them from the bazaar. In Iran many students buy readymade flashcards from bookstores and many teachers emphasize the importance of students making their own cards. This study was done to determine difference between these two methods used for learning English vocabulary.

Other studies have been done relating to this topic, for example Eslahkar [4], states " One way to add new words to one,s vocabularies is by locating words in dictionary and learning what they mean. But this is a slow process to increase word power. "

A study (Eslahkar [3],) also mentions that vocabulary is a major component of language learning that has been the object of numerous studies, each of which has made its own contribution to the field.

(Hedge [4]) mentions that learning vocabulary is regularly overlooked in the literature related to English language teaching and learning. In the 1970 s Wilkins wrote that linguists have had remarkably little to say about vocabulary learning and there are very few studies of any practical interest to language teachers (1972:109). Almost a decade later, Meara commented that vocabulary acquisition had received little research attention from applied linguistics (1980:221). In a later study Ellis [6] expressed the view that the situation had not changed significantly.

(Nima Shakouri [9]) states that discussions of vocabulary learning are often divided into intentional learning and incidental learning. Intentional learning is that designed, planned for, or intended by teachers or students.

There is no doubt that vocabulary is a necessary part of learning a language.

(Katamba [7]) states that the assumption that languages contain words is taken for granted by most people. Even illiterate speakers know that language consits of words.

Accordingly, words are a nessessary part of any language so one might have had a schematic and manageble study in this field and it is supposed that the only way for boosting this knowledge is to study words within their context.

Katamba [7], maintains that morphology is the study of word-structure. The claim that words have structure might come as a surprise because normally speakers think of words as invisible units of meaning. He continues the assertion to by explaining that this is probably due to the fact that many words are morphologically simple.

As part of the simplicity of words, every learner should pay attention to having at least 2000 suitable words and this number must be increased to 17000 words for more educated people.

(Dr. Seyyed Akbar Mirhassani [2]) states that to assist students, the present book has adopted a new approach that provides three reading and a variety of comprehension and vocabulary questions, practical etymology, idomatic and structure exercises to help learners develop comprehension and to integrate new ideas with their knowledge and experience of the world.

It shows the importance of vocabulary as the writer focuses on vocabulary as an element in developing comprehension. 


\subsection{Statement of the Problem}

The results of the present study may confirm or deny the hypothesis that determines that students learn more English vocabulary if they use the traditional method of making flashcards by hand as opposed to buying ready made flashcards from bookstores. This study tries to answer this assumption step by step.

According to the above mentioned references, it was determined that there is a problem in the field that requires further investigation. This study that was done accordingly to determine the root cause of the problem in relation to learning methods used by pre-university students.

The second aspect of meaning involves sense relations that exist among words (Hedge [4]). This implies that we can make a good relationship between a word and its relation to others in a network of meaning. This raises the question of what method can be best applied to achieve this result? And how is this related to the commonly accepted ways of learning vocabulary?

It is well known that vocabulary is the key to acquisition of knowledge in any langauge and an extended vocabulary that can be applied fluently and precisly determines effective language learning. Some students at pre-university level suffer from experiencing a good and ongoing progress in teaching methodology, such that less English words are learnt in classes and students find such learning very difficult.

We know that learning a language cannot be achieved without considerable attention being paid to learning vocabulary. In order to address this problem in a new way, it was decided to test student learning. In fact students are facing a new phenomenon in learning language and that is loosing memory of word meanings. This could inhibit learning new words in English among learners of English as a second language.It seems that one of the main problems in learning and acquiring a second language is a limited vocabulary.

(Hedge [4]) recommends a well - used frequency list; that of West [5], in which there are some 2,000 headwords, each of which is accompanied by its inflected forms and a list of common derivate and compounds. Possessing a useful and extended bank of words requires attention and must not be ignored. This result is achievable if students work hard and use flashcards. Another problem is that of word pronunciation.

A study by Beare [1], reports that spelling words in English are challenging. As a matter of fact, many native English speakers have problems with spelling. One of the main reasons for this is that very many English words are not spelled as they are spoken. This difference between pronunciation and spelling causes a lot of confusion.

Some pre-university students try to learn more English words and expand their vocabulary, but memory of these words is soon lost. This often happens because they do not use flash cards.Teachers do not often make the students work regularly on words by useful techniques such as using flashcards.

Students often attempt to learn by writing down words and recording meanings in front of them. Second language learners often lack a scientific methodology, so words are not remembered. Students need a practical approach to learning new words.

A study by Yorkey [10], states that there are three possible ways to learn meanings of unfamiliar words. One of which is to interrupt reading immediately on encountering an unfamiliar word and look the word up in a dictionary. This is the safest way but it needs to be adopted appropriately, however, only if the following two ways are impossible. Using knowledge of a word stem and word formation, an intelligent guess can be made as to the meaning of a new word.

\subsection{Research Question and hypothesis}

This study aims to find answers to research questions related to using flashcards for language learning among preuniversity students.

Does using flashcards really affect students' ability to learn vocabulary?

What are the differences between the two selected groups in terms of studying words using flashcards?

\section{Method}

\subsection{Participants}

Participants in this study were 40 pre-university students attending ParsAbad Moghan City , Farzanegan high school (all female but from two separate classes). The participants were given a pre-test to ensure that their vocabulary levels were at the same level. 


\subsection{Instruments and Materials}

The study was conducted according to the following steps:

\subsection{Analysis of Covariance}

For the given hypothesis, the results of analysis of Covariance were applied to determine any meaningful difference between the two groups of pre university student scores; between the group that used hand made flashcards and the one that used flashcards bought from a bookstore. This evaluation was done from results of the pre-test.

Table (1) includes descriptive statistics. It relates to the post-test variable for both groups. The mean for marks in the post-test for group 1 is 9.8 and the mean for the second group is 13.20.

Table 1 : Descriptive Statistics

\begin{tabular}{cccc}
\hline Group & Mean & Std. Deviation & $\mathrm{N}$ \\
\hline 1.00 & 9.8000 & 4.02100 & 20 \\
2.00 & 13.2000 & 2.64774 & 20 \\
Total & 11.5000 & 3.77577 & 40 \\
\hline
\end{tabular}

Table (2) relates to the Levene's Test of Equality of Error Variances. With attention to the information in the table, since p-value of the test is (0.290) and that the evaluation is bigger than 0.05, then these results were applied as the dependent variable for the post-test is equivalent in both groups.

Table 2: Levine's Test of Equality of Error Variances

\begin{tabular}{cccc}
\hline F & df1 & df2 & Sig. \\
\hline 1.152 & 1 & 38 & .290 \\
\hline
\end{tabular}

Table (3) shows the main results for Analysis of Covariance. The value of (F) relating to the effects of group equals 9.517 and the p-value of the meaning is 0.004 .

Then it can be determined that scores of the Control and Experimental groups had meaningful difference. Attention to these results shows that post-test is 9.8 for group 1 and 13.20 for group 2, it is understood that the pre-university students who bought readymade flashcards from a bookstore (here they are called Experimental group 2) were able to learn vocabulary better than students in group 1 (Control group) who made their own flashcards.

Table 3: Tests of Between-Subjects Effects

\begin{tabular}{|c|c|c|c|c|c|}
\hline Source & $\begin{array}{c}\text { Type III Sum of } \\
\text { Squares }\end{array}$ & df & Mean Square & $\mathrm{F}$ & Sig. \\
\hline Corrected Model & $116.097^{\mathrm{a}}$ & 2 & 58.049 & 4.882 & .013 \\
\hline Intercept & 193.017 & 1 & 193.017 & 16.235 & .000 \\
\hline pre & .497 & 1 & .497 & .042 & .839 \\
\hline group & 113.145 & 1 & 113.145 & 9.517 & .004 \\
\hline Error & 439.903 & 37 & 11.889 & & \\
\hline Total & 5846.000 & 40 & & & \\
\hline Corrected Total & 556.000 & 39 & & & \\
\hline
\end{tabular}

\subsection{Extra Findings}

Information obtained from results of this study was directed to the two groups separately. Firstly to group 1 (control group) to determine any meaningful difference between the marks of students in post-tests and pre-tests of the Control and the Experimental group.

\subsection{The Control Group}

In the first part, the control group was investigated to determine any meaningful difference between scores of students in pre-tests and post-tests. In other words, we wanted to know the effects of making and preparing flashcards in learning vocabulary by preuniversity students. 
For this purpose, we used the Paired T test. Table (4) that include descriptive statistics on results of pre-tests and posttests for students within the control group. Mean results of the pre-tests is 15.6 and the mean for posttest is 9.8 .

Table 4 : Paired Samples Statistics

\begin{tabular}{ccccc}
\hline & & Mean & N & Std. Deviation \\
\hline Pair 1 & Pre-test & 15.6000 & 20 & 3.01575 \\
& Post-test & 9.8000 & 20 & 4.02100 \\
\hline
\end{tabular}

The table shown below (Table 5) includes comparison of means by the Paired T test pre and post-test exams. Since the p-value is less than 0.05 , it can be determined that there is meaningful difference between pre and post test remarks among students in the control group. However, according to results of the post-test, for which evaluations were less than those of the pre-test, results show that using hand made flashcards for learning vocabulary had a negative impact on results of learning vocabulary, on the other hand it did not boost the extent of vocabulary among students in the control group.

Table 5 : Paired Samples Test

\begin{tabular}{ccccc}
\hline & & $\mathrm{t}$ & $\mathrm{df}$ & Sig. (2-tailed) \\
\hline Pair 1 & Pre test - post test & 5.420 & 19 & .000 \\
\hline
\end{tabular}

\subsection{The experimental Group}

As for group one, the Experimental group was investigated in the same way as the Control group to determine any meaningful difference between results of pre and post-tests in this group. Table (6) includes descriptive statistics for pre and post-tests belonging to the experimental group, in which results determined that mean in pretest, is 14.2 and post test is 13.2 .

Table 6: Paired Samples Statistics

\begin{tabular}{ccccc}
\hline & & Mean & N & Std. Deviation \\
\hline Pair 1 & Pre-test & 14.2000 & 20 & 3.23793 \\
& Post-test & 13.2000 & 20 & 2.64774 \\
\hline
\end{tabular}

For comparison of means between pre and post tests, it was necessary to apply the Paired T test to the Experimental Group. Since the p-value (0.311) is more than 0.05, results determine no meaningful difference between pre-test and post-test results for the experimental group. The mean of students, scores was evaluated as one score less than that of the pretest but this reduction is not remarkable from the point view of statistical knolwdge. Please refer to Table (7).

Table 7 : $\quad$ Paired Samples Test

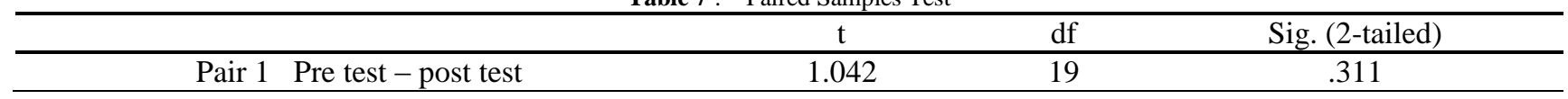

\section{Conclusions and implications}

\subsection{Conclussions}

This study was done to address the research question of does the use of flashcards have an effect on students' ability to learn vocabulary? The null hypothesis was as follows: making flashcards with traditional methods can boost a student's ability in learning vocabulary, as (Yorkey [10]) has argued. But the results of this study were contrary to that assertion. The null hypothesis was not proven. It is assumed that there may be some problems with students, related to background knowledge.

It is well known that learning vocabulary is not given adequate attention by some teachers of SL. Most English teachers pay more attention to grammar instruction than to teaching vocabulary. However, teachers should choose the most appropriate method to enable high school students to achieve the good results.

This lack of attention to learning vocabulary is regarded as a serious problem for expanding vocabluary learnt by language students.

There is much software available in the field that helps students expand their vocabulary. Technological progress may be used to overcome this time consuming strategy of handwriting and now is the time for such change. Students who use readymade flashcards can learn better than those that make their own flashcards by traditional methods. Students can learn a variety of words faster and can memorize many words in a bank of vocabulary. 


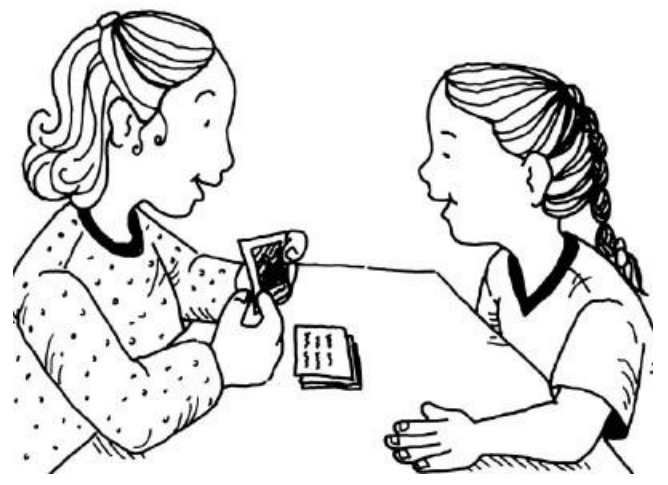

Fig. 2

\subsection{Pedagogical implications}

Certainly, the findings of this studty can help students as well as teachers to pay attention to the use of flashcards in learning and teaching vocabulary. It might be very important that students learn words through text and in an appropriate context and it is recommended that designers of flashcards pay attention to this very important consideration in making and designing such resources for learning English as a second language.

\section{References}

[1] Beare, K. (n.d.). Retrieved 2014, from http://esl.about.com/od/writingintermediate/a/1_spell.htm

[2] Seyyed Akbar Mirhassani, S. M. Reading (2). Tehran: SAMT. (2001).

[3] Eslahkar, M.The effect of Using Vocabulary Flash Card on Iranian Pre-University Students, Vocabulary Knowledge.5, (2012, June), p. 134.

[4] Hedge, T, Teaching and Learning in the Language Classroom. London, England: Oxford University Press, (2000).

[5] West (1953) (as cited in Hedge, T , 2000) Teaching and Learning in the Language Classroom .

[6] Ellis (1995) (as cited in Hedge, T , 2000) Teaching and Learning in the Language Classroom

[7] Katamba, F. Morphology. (P. N. Burton-Roberts, Ed.) University of Newcastle upon Tyne, (1993).

[8] Michael J . Lawson, Donald Hogben. (n.d.). The Vocabulary-Learning Strategies of Foreign -Language Studets. Flinders University.

[9] Nima Shakouri, K. M., The Impact of Using Flash Cards on Promoting University Students , Knowledge of Vocabulary. 1, (2012).

[10] Yorkey, R. C., Study Skills. (H. S.Thomassen, Ed.) United States of America: Library of Congress, (1970).

[11] Din,F.S.,\& Wienke, E. (2001). The Effect of Flash Card Use on Students , Comprehension of Chemistry Vocabulary. ERIC Document 458115.

[12] Allen,F.V. (1998). Techniques in Teaching Vocabulary. New York: Oxford University Press.

[13] Bowen. J.J., Madson,H., \& Hilferty,A. (1985). TESOL techniques and procedures. London: Newbury House. 